9 Kannell WB. Role of diabetes in cardiac diseases. Conclusions from population studies. In: Zonerich S, ed. Diabetes and the heart. Springfield, Illinois: Thomas, 1978:97-122.

10 Beckles CLA, Miller GJ, Kirkwood BR, Alexsis SD, Carson DC, Byman NTA. High total and cardiovascular disease mortality in adults of Indian descent in Trinidad, unexplained by major coronary risk factors. Lance 1986;i:1298-1301.

11 World Health Organisation. Cardiovascular survey methods. WHO Monogr Ser 1968; No 56:137-41.

12 Bertrand ME, Lefevre JM, Laisne CL, Rousseau MF, Carre AG, Lekieffre JP. Coronary arteriography in acute transmural myocardial infarction. Am Heart f 1979;97:61-9.

13 McConahay DR, McCallister BD, Hallerman FJ, Smith RE. Comparative quantitative analysis of the electrocardiogram and vectorcardiogram: correlations with the coronary angiogram. Circulation 1970;42:245-59.

14 WHO Study Group. Diabetes mellitus. WHO Tech Rep Ser 1985; No 727.

15 Balasubramanian V, Lahiri A, Paramasivan R, Raftery EB. Verapamil in chronic stable angina: a controlled study with computerised multistage chronic stable angina: a controlled st
treadmill exercise. Lancet 1980;i:841-4.

16 Lahiri A, Rodrigues EA, Al-Khawaja I, Raftery EB. Effects of a new vasodilating beta-blocking drug carvedilol on left ventricular. function in stable angina pectoris. Am f Cardiol 1987;59:769-74.

17 Hains ADB, Al-Khawaja I, Hinge D, Lahiri A, Raftery EB. Radionuclide lef ventricular ejection fraction: a comparison of three methods. Br Heart $\mathcal{J}$ $1987 ; 57: 242-6$

18 O'Hara MJ, Lahiri A, Whittington JR, Crawley JCW, Raftery EB. Detection of high risk coronary artery disease by thallium imaging. Br Heart $f$ 1985;53:616-23.

19 Judkins MP. Selective coronary arteriography: a percutaneous transfemoral technic. Radiology 1967;89:815-23.

20 Sones FM, Shirey EK. Cine coronary arteriography. Modern Concepts of Cardiovascular Disease 1962;31:735-9.

21 Humphries JO'N, Kuller L, Ross RS, Friesinger GC, Page EE. Natural history of ischemic heart disease in relation to arteriographic findings: a twelve year study of 224 patients. Circulation 1974;49:489-97.
22 Lowry PJ, Glover DR, Mace PJE, Littler WA, Coronary artery disease in Asians in Birmingham. Br Heart $\mathcal{f}$ 1984;52:610-3.

23 Braunwald $\mathrm{E}$ ed. Heart disease. In: A textbook of cardiovascular medicine. Washington, DC: W B Saunders, 1984:467-87.

24 Quinones MA, Waggoner AD, Reduto LA, et al. A new simplified and accurate method for determining ejection fraction with two-dimensional echocardiography. Circulation 1981;64:744-53.

25 Morris JA, Gardner MJ. Calculating confidence intervals for relative risk (odd ratio) and standardised ratios and rates. Br Med $\mathcal{F}$ 1988;296:1313-6.

26 Maseri A, L'Abbate A, Baroldi G, et al. Coronary vasospasm as a possible cause of myocardial infarction: a conclusion derived from the study of preinfarction angina. $N \mathrm{Engl} f \mathrm{Med}$ 1978;299:1271-7.

27 Chapman I. The cause-effect relationship between recent coronary artery occlusion and acute myocardial infarction. Am Heart $\mathcal{f}$ 1974;49:1-3.

28 Miller GJ, Alexis SD, Beckles GLA, Byan NTA, Price SGL. Serum lipoproteins and susceptibility of men of Indian descent to coronary heart disease. The St James survey, Trinidad. Lancet 1982;ii:200-3.

29 Thomas I, Gupta S, Sempos C, Cooper R. Serum lipids of Indian physician living in the US compared to US born physicians. Atherosclerosis 1986;61: 99-106.

30 Katz AM, Messineo FC. Lipid membrane interactions and the pathogenesis of ischemic damage in the myocardium. Circ Res 1981;48:1-15.

31 Liedtke AT, Nellis S, Necly JR. Effects of excess free fatty acids on mechanical and metabolic function in normal and ischemic myocardium in swine. $C$ ir Res 1978;43:652-6.

32 Opie LH. Metabolism of free fatty acids, glucose and catecholamines in acute myocardial infarction. Am $\mathcal{f}$ Cardiol 1975;36:938-42.

33 Cabin HS, Roberts WC. Quantification of amounts of coronary arteria narrowing in patients with types II and IV hyperlipoproteinemia and in those with known normal lipoprotein patterns. Am Heart f 1981;101:52-8.

34 Wojciechowski AP, Kughes LO, Winder AF, Pohl JEF, Raftery EB. Exercise testing in asymptomatic patients with familial hypercholesterolaemia [Abstract]. Clin Sci 1988;75 (suppl 19):30.

(Accepted 22 March 1989)

\title{
Optimisation of positive end expiratory pressure for maximal delivery of oxygen to tissues using oesophageal Doppler ultrasonography
}

\author{
Mervyn Singer, David Bennett
}

\begin{abstract}
Objective-To assess oesophageal Doppler ultrasonography as a convenient means of optimising positive end expiratory pressure for maximal delivery of oxygen to tissues.

Design-Measurements of blood flow, arterial oxygen saturation, and cardiac output by thermodilution (when available) at baseline and at 20-30 minutes after each incremental increase $(2 \cdot 5-5 \cdot 0 \mathrm{~cm}$ $\mathrm{H}_{2} \mathrm{O}$ ) in positive end expiratory pressure to a maximum of $20.0 \mathrm{~cm} \mathrm{H} \mathrm{H}_{2} \mathrm{O}$. If the cardiac output fell by more than $15 \%$ measurements were repeated after stepwise decreases in positive end expiratory pressure. No other manoeuvre such as endotracheal suction or changing ventilator settings, drug or fluid dosage, or the patient's position was performed for at least one hour before the start of the study or during it.
\end{abstract}

Setting-Intensive care unit.

Participants-10 Patients being mechanically ventilated for acute respiratory failure who had stable haemodynamic and blood gas values and required a fractional inspired oxygen concentration of $\geqslant 0 \cdot 45$. They were assessed on a total of 11 occasions.

Interventions - Incremental increases in positive end expiratory pressure followed when indicated by stepwise decreases.

End point-The positive end expiratory pressure providing maximal delivery of oxygen to tissues.

Measurements and main results-Arterial oxygen saturation increased with positive end expiratory pressure in all patients by an average of $6 \cdot 1 \%$. In nine of the 11 studies, however, cardiac output fell by $15 \%$ to $30 \%$ after the second increment. On the two other occasions cardiac output and oxygen delivery rose by up to $54 \%$. Positive end expiratory pressure was decreased on seven occasions; there was consider- able individual variation in the time taken for cardiac output to rise and arterial oxygen saturation to fall. In six patients good agreement was seen between the results from Doppler ultrasonography and thermodilution, the mean of the differences being $-0.3 \%$ with narrow limits of agreement $(-14.4 \%$ to $13.9 \%)$.

Conclusions-Oesophageal Doppler ultrasonography is a rapid, safe, and reliable technique for optimising positive end expiratory pressure to obtain maximal delivery of oxygen to tissues. The results show the need to consider haemodynamic consequences when altering positive end expiratory pressure.

\section{Introduction}

Positive end expiratory pressure is commonly used to increase the oxygenation of blood in patients who are being mechanically ventilated. The increased oxygenation, however, has to be offset against a depression of cardiac output, which occurs at varying positive end expiratory pressures in different patients ${ }^{1.8}$ and with time in individual patients. Factors such as left ventricular preload ${ }^{457}$ and right ventricular function ${ }^{9}$ play a part in determining when and to what extent this decrease in output occurs. Increasing positive end expiratory pressure will therefore alter unpredictably the equation of oxygen delivery $=$ cardiac output $\times$ arterial oxygen content. The delivery of oxygen may even fall below the starting value and pass unrecognised without the monitoring of cardiac output; the perceived improvement in the oxygenation of blood may in fact disguise an appreciable drop in the delivery of oxygen to the tissues. Indeed, criticism has recently been voiced about the current trend of increasing positive end expiratory pressure without due regard to the haemodynamic consequences. ${ }^{10}$

Thermodilution is the main technique used in inten-
Sessorial Unit,

London W1N 8AA. 
sive care units to measure cardiac output. Pulmonary artery catheterisation is not, however, without risk, the reported morbidity being $3 \cdot 6-7 \cdot 2 \%^{112}$; not all units are experienced in its use, ${ }^{13}$ and it may not be deemed necessary in some patients who require positive end expiratory pressure. We previously described a new oesophageal Doppler system that accurately follows changes in cardiac output when compared with thermodilution. ${ }^{14}$ Furthermore, by this technique alone volumetric cardiac output can be estimated with $85 \%$ accuracy. In view of its ease of use, safety, rapidity, and comparative non-invasiveness it should be a useful means of optimising positive end expiratory pressure to maximise the delivery of oxygen to tissues and to confirm that other indications of positive end expiratory pressure - for example, lowering inspired oxygen concentrations-do not have too deleterious an effect on oxygen delivery. We investigated this potential application of oesophageal Doppler ultrasonography, using thermodilution when available for comparison, to follow the percentage change in cardiac output on altering the positive end expiratory pressure.

\section{Patients and methods}

Patients being mechanically ventilated for acute respiratory failure were eligible for the study provided that they had stable haemodynamic and blood gas values and required an inspired oxygen concentration of $\geqslant 0 \cdot 45$. Those with abnormal blood clotting profiles or oesophageal disease were excluded. All were adequately sedated, and paralysed if necessary, for continuous mandatory ventilation with constant tidal volumes of $12-15 \mathrm{ml} / \mathrm{kg}$ delivered by either Veolar (Hamilton Medical, Rhazuns, Switzerland), Erica (Engstrom, Stockholm, Sweden), or Servo 900B ventilators (Siemens, Sunbury on Thames, Middlesex).

Physical manoeuvres such as endotracheal suction and turning the patient were not performed and ventilator settings, drug doses, and the administration of boluses of fluid were not changed for at least one hour before the start of the study. Similarly, no alterations were made during the course of the investigation other than changing the positive end expiratory pressure. The study was discontinued if another manoeuvre had to be performed that might have disturbed the steady state-for example, suction.

A $5 \cdot 1 \mathrm{MHz}$ continuous wave oesophageal Doppler transducer connected to a spectral analyser system (Doptek, Chichester, Sussex) was used. The transducer was inserted through the mouth to a depth of about $30-40 \mathrm{~cm}$ until blood flow was detected. It was focused on the midstream flow of the descending thoracic aorta by rotating the probe until velocity waveforms with minimal spectral dispersion were seen that were characteristic of midstream blood flow in the aorta. ${ }^{1+}$ The area of each waveform - the velocity-time integral or stroke distance-is a linear measure of the left ventricular stroke volume that passes through the descending thoracic aorta. The stroke distance and heart rate were computed semiautomatically by using a

TABLE I-Characteristics of patients studied

\begin{tabular}{|c|c|c|c|}
\hline $\begin{array}{l}\text { Case } \\
\text { No }\end{array}$ & Sex & $\begin{array}{c}\text { Age } \\
\text { (years) }\end{array}$ & Condition \\
\hline 1 & M & 53 & Adult respiratory distress syndrome after intestinal obstruction \\
\hline 2 & $\mathrm{~F}$ & 32 & $\begin{array}{l}\text { Lymphoma, cytomegalovirus pneumonitis, left ventricular failure secondary to cytotoxic } \\
\text { treatment }\end{array}$ \\
\hline 3 & M & 57 & Adult respiratory distress syndrome after trauma \\
\hline 4 & M & 56 & Adult respiratory distress syndrome, sepsis \\
\hline 5 & $\mathrm{~F}$ & 63 & Pneumonia \\
\hline 6 & $\mathrm{M}$ & 59 & Pneumonia, long term airflow limitation \\
\hline 7 & M & 29 & Chickenpox pneumonia \\
\hline 8 & $\mathrm{~F}$ & 65 & Pneumonia \\
\hline 9 & $\mathrm{M}$ & 19 & Adult respiratory distress syndrome after strangulation \\
\hline 10 & M & 29 & Adult respiratory distress syndrome, pneumonia \\
\hline
\end{tabular}

TABLE II - Positive end expiratory pressure $\left(\mathrm{cm} \mathrm{H}_{2} \mathrm{O}\right)$ and percentage changes in cardiac output and delivery of oxygen to tissues in 10 patients studied by oesophageal Doppler ultrasonography. Blank values indicate no change

\begin{tabular}{llcc}
\hline Case & Positive end & Cardiac & Tissue oxygen \\
No & expiratory pressure & output & delivery
\end{tabular}

$1 \quad\left[\begin{array}{c}0 \\ 5 \\ 10 \\ 15\end{array}\right.$

$\left\{\begin{array}{l}5 \\ 15 \\ 20\end{array}\right.$

2

(18)

$2^{\star}$

3

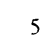

6

8 10

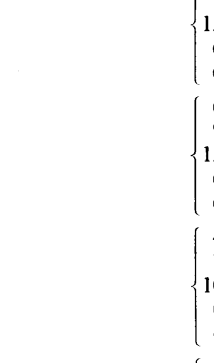

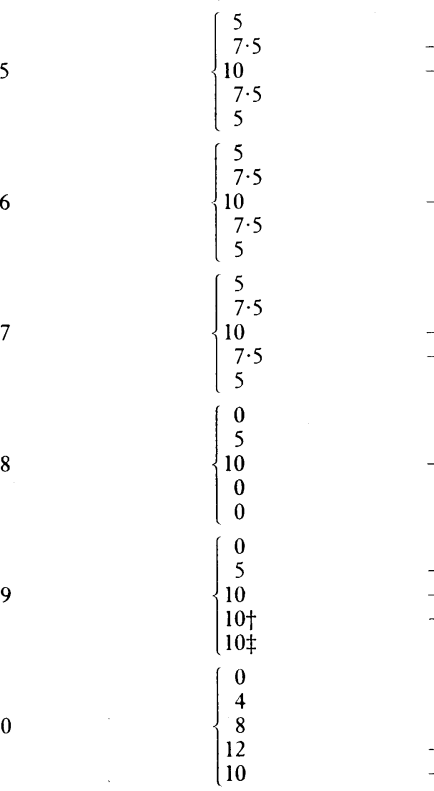

$+10 \quad+2$

$\begin{array}{lll}15 & +10 & +16 \\ 20 & +17 & +25\end{array}$

6
9

-2
+10

$+40+54$

$-13-10$

$\begin{array}{ll}-19 & -8 \\ -19 & -16 \\ -11 & -11\end{array}$

$-7$

-7
-29
-31

-6
-26

$-26$

$-28$

$-16$

-17
-18

$-18$

$-12$

$-18$

$-13$

-10
-15
-4

+2
-4
-19

-4
-19
+2

$+2$

-9
-16

$-8$

-8
-5

$\star$ Five days later. †Colloid bolus of $200 \mathrm{ml}$ †Colloid bolus of $700 \mathrm{ml}$.

light pen and integral software. A minimum of five waveforms encompassing a respiratory cycle were measured and the results averaged to provide an index of total body cardiac output.

Haemoglobin concentration and arterial oxygen saturation were measured with an OSM2 Hemoximeter (Radiometer, Copenhagen, Denmark) in heparinised blood drawn from an indwelling radial or femoral line. Cardiac output was measured by thermodilution in patients with a pulmonary artery flotation cathether (American Edwards Labs, Santa Ana, California). Iced $5 \%$ dextrose $(5 \mathrm{ml}$ aliquots) was injected and cardiac output measured by a COM-1 computer (American Edwards Laḅs, Santa Ana, California). The average of three outputs falling within $10 \%$ of each other was taken.

The starting positive end expiratory pressure was noted and after baseline measurements were performed the pressure was increased by increments of $2 \cdot 5-5 \cdot 0 \mathrm{~cm} \mathrm{H}_{2} \mathrm{O}$ to a maximum of $20 \cdot 0 \mathrm{~cm} \mathrm{H}_{2} \mathrm{O}$. All measurements were repeated 20-30 minutes after each change. Positive end expiratory pressure was not increased further if the fall in cardiac output exceeded $15 \%$, in which case it was reduced incrementally with 
measurements once again repeated 20-30 minutes after each change.

An index of oxygen delivery was calculated from the formula (haemoglobin concentration $\times 1 \cdot 34 \times$ arterial oxygen saturation $) \times($ stroke distance $\times$ heart rate $)$.

The percentage change in cardiac output from baseline values measured by Doppler ultrasonography and thermodilution was compared according to the method described by Bland and Altman. ${ }^{\text {is }}$

The study was approved by the hospital district medical ethics committee.

\section{Results}

Ten patients were studied on a total of eleven occasions, and their details are shown in table I.

Arterial oxygen saturation increased in all patients after increases in positive end expiratory pressure. The mean baseline saturation of $90 \cdot 7 \%$ (SD $8.5 \%$ ) rose to $96.2 \%(6 \cdot 1 \%)$ at the highest value, an average increase of $6 \cdot 1 \%$. In all but two patients, however, the increase in positive end expiratory pressure resulted in reductions in cardiac output that exceeded $15 \%$ by the second increment (range $-15 \%$ to $-30 \%$ ). Corresponding decreases of $-2 \%$ to $-25 \%$ were seen in the delivery of oxygen to the tissues (table II).

Increases in cardiac output and delivery of oxygen to the tissues of $40.4 \%$ and $53.5 \%$ respectively occurred in one patient with left ventricular failure (case 2) when positive end expiratory pressure was increased from 6 to $18 \mathrm{~cm} \mathrm{H} \mathrm{H}_{2} \mathrm{O}$. The procedure was repeated five days later when the heart failure was controlled; on this occasion a fall in cardiac output of $19 \cdot 3 \%$ was seen on increasing the pressure from 6 to $12 \mathrm{~cm} \mathrm{H}_{2} \mathrm{O}$. One patient (case 9) became increasingly hypotensive and oliguric after positive end expiratory pressure was increased from 0 to $10 \mathrm{~cm} \mathrm{H}_{2} \mathrm{O}$ and recovered after having been given a colloid bolus of $700 \mathrm{ml}$.

Measurements after decreases in positive end expiratory pressure were obtained on seven occasions; we found considerable individual variation in the time taken for cardiac output to rise and arterial oxygen saturation to fall.

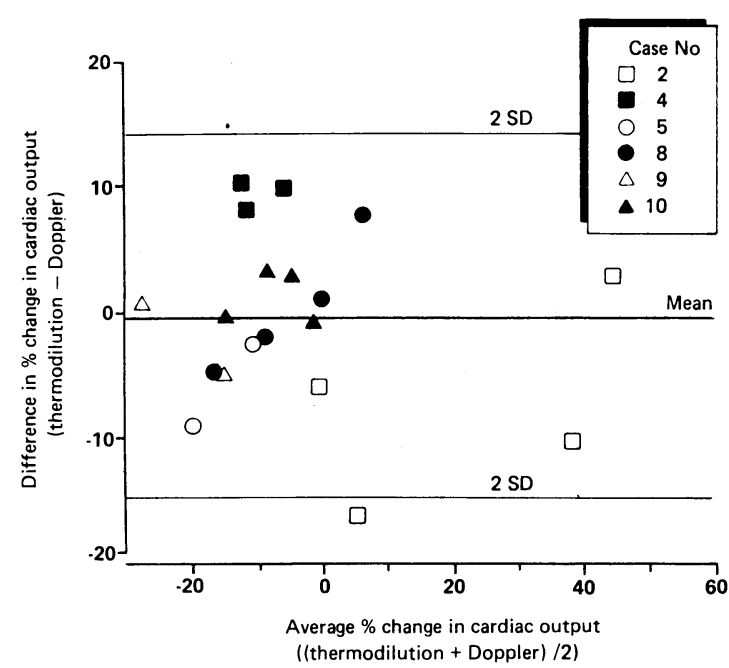

Comparison of percentage change in cardiac output with positive end expiratory pressure measured by thermodilution and oesophageal Doppler ultrasonography in six patients

Measurements from thermodilution and Doppler ultrasonography were obtained simultaneously in six patients. A total of 25 paired measurements were obtained, providing 19 changes from baseline values. The mean of the differences between the values obtained by the two techniques was $-0.3 \%$ with narrow limits of agreement ( $-14 \cdot 4 \%$ to $13 \cdot 9 \%$ ) (figure).

\section{Discussion}

Oesophageal Doppler ultrasonography may be used to show the variation in haemodynamic response to increasing positive end expiratory pressures both between patients and in the same patient over time. Large decreases in cardiac output may be easily recognised and, in conjunction with arterial blood sampling, the optimum pressure found for maximal oxygen delivery.

Positive end expiratory pressure is a useful means of improving the oxygenation of arterial blood. Through its use, however, the delivery of oxygen to tissues may actually fall, which may pass unrecognised. Whether oxygen delivery is the ideal variable for defining the best positive end expiratory pressure is debatable. Nevertheless, we are concerned that too large a depression of cardiac output by positive end expiratory pressure may prove deleterious, especially when oxygen consumption is dependent on delivery. ${ }^{16}$ Even small positive end expiratory pressures may result in large falls in cardiac output. This was recognised soon after positive end expiratory pressure was first used,' and the importance of measuring oxygen delivery has been emphasised by several authors..$^{1-310}$ Multiple injections for thermodilution over short periods are, however, time consuming and may result in an undesirable fluid load. Furthermore, many British intensive care units use pulmonary artery catheterisation sparingly, if at all,,$^{13}$ and this is probably reflected in many other countries.

Oesophageal Doppler ultrasonography thus provides a useful alternative means of determining the optimal positive end expiratory pressure for the maximal delivery of oxygen to body tissues. The transducer is easily inserted and excellent signals are uniformly obtained within one to two minutes. Because of the stability of the transducer the error in recording data is negligible; the transducer may either be left in situ for days without complication or be reinserted as necessary. The good agreement shown with thermodilution in our patients suggests that there are no large changes in the ratio of descending aortic flow to total cardiac output. This implies that positive end expiratory pressure does not appreciably redistribute regional cardiac output.

Apart from optimising the delivery of oxygen to the tissues oesophageal Doppler ultrasonography could be used to ensure that attempts to improve arterial blood oxygenation, reduce venoarterial admixtures, or lower inspired oxygen concentrations to non-toxic values by increasing positive end expiratory pressure do not have too deleterious an effect on the oxygen delivery. Furthermore, the efficacy of therapeutic manoeuvres such as fluid administration ${ }^{3816}$ given to restore the delivery of oxygen to tissues may be assessed.

In conclusion, oesophageal Doppler ultrasonography offers a reliable, safe, rapid, continuous, and comparatively non-invasive means of finding the optimal positive end expiratory pressure for the maximal delivery of oxygen to tissues in critically ill patients. It can be easily performed at regular intervals as any important change in haemodynamic state, either spontaneous or therapeutic, may alter the optimal positive end expiratory pressure. Increasing positive end expiratory pressure to improve the oxygenation of blood may result in major haemodynamic disadvantages, even at low values. Our results highlight the need to monitor circulatory changes occurring in consequence.

1 Lutch JS, Murray JF. Continuous positive pressure ventilation: effects on systemic oxygen transport and tissue oxygenation. Ann Intern Med 1972;76:193-202.

2 Suter PM, Fairley HB, Isenberg MD. Optimum end-expiratory pressure in patients with acute pulmonary failure. $N$ Engl f Med 1975;292:284-9.

3 Walkinshaw M, Shoemaker WC. Use of volume loading to obtain preferred 
evels of positive end expiratory pressure. A preliminary study. Crit Care Med 1980;8:81-6.

4 Calvin JE, Driedger AA, Sibbald WJ. Positive end-expiratory pressure (PEEP) does not depress left ventricular function in patients with pulmonary edema. Am Rev Respir Dis 1981;124:121-8.

5 Prewitt RM, Oppenheimer L, Sutherland JB, Wood LDH. Effect of positive end-expiratory pressure on left ventricular mechanics in patients with hypoxemic respiratory failure. Anesthesiology 1981;55:409-15.

6 Ellman H, Dembin H. Lack of adverse hemodynamic effects of PEEP in patients with acute respiratory failure. Crit Care Med 1982;10:706-11

7 Grace MP, Greenbaum DM. Cardiac performance in response to PEEP in patients with cardiac dysfunction. Crit Care Med 1982;10:358-60.

8 Jardin F, Farcot J-C, Boisante L, Curien N, Margairaz A, Bourdarias JP. Influence of positive end-expiratory pressure on left ventricular performance. N kingl f Med 1981;304:387-92.

9 Schulman DS, Biondi JW, Matthay RA, Barash PG, Zaret B, Soufer R. Effect of positive end-expiratory pressure on right ventricular performance. Importance of baseline right ventricular function. Am J Med 1988;84:57-67.
10 Civetta JM. After quibbles and contrasts, concepts and caveats [Editorial]. Chest 1988;93:697-8.

11 Foote GA, Schabel SI, Hodges M. Pulmonary complications of the flowdirected balloon-tipped catheter. $N$ Engl I Med 1974;290:927-31.

12 Elliott CG, Zimmerman GA, Clemmer TP. Complications of pulmonary artery catheterisation in the care of critically-ill patients. A prospective study. Chest 1979;76:647-52.

13 Singer M, Bennett ED. Invasive hemodynamic monitoring in the United Kingdom. Enough or too little? Chest 1989;95:623-6.

14 Singer $M$, Clarke J, Bennett ED. Continuous hemodynamic monitoring b esophageal Doppler. Crit Cure Med (in press).

15 Bland JM, Altman DG. Statistical methods for assessing agreement between two methods of clinical measurement. L L ancet 1986;i:307-10.

16 Nelson LD, Houtchens BA, Westenkow DR. Oxvgen consumption and optimum PEEP in acute respiratory failure. Crit Care Med 1982;10:857-62.

(Accepted 23.March 1989)

\title{
Oral rehydration formula containing alanine and glucose for treatment of diarrhoea: a controlled trial
}

\author{
F C Patra, D A Sack, A Islam, A N Alam, R N Mazumder
}

\section{Abstract}

Objective-To determine whether adding L-alanine to the glucose based oral rehydration solution recommended by the World Health Organisation would improve its efficacy in treating acute diarrhoea.

Design-Randomised double blind controlled trial of oral rehydration solution containing $\mathrm{L}$-alanine and glucose.

Setting-Inpatient service of a hospital treating diarrhoea.

Patients-97 Male patients aged 6-59 years admitted to the hospital with acute and severe dehydration due to diarrhoea associated with Vibrio cholerae or enterotoxigenic Escherichia coli. Forty nine received the standard glucose based oral rehydration solution (control group) and 48 this solution with alanine added (study group).

Interventions - All of the patients received rapid intravenous acetate solution for the initial four hours after admission, which fully corrected the signs of dehydration. They were then admitted to the study and randomised. Immediately after the intravenous treatment oral rehydration treatment was started. All of the patients received oral tetracycline for $\mathbf{4 8}$ hours, starting 24 hours after start of the study. If signs of dehydration reappeared during oral treatment patients were given rapid intravenous acetate solution until they were fully corrected and then continued to take the assigned oral rehydration solution.

End point-Passage of the last watery stool.

Measurements and main results-The median stool output $/ \mathrm{kg}$ body weight during the initial 24 hours of oral rehydration treatment and until diarrhoea stopped was reduced in the study group compared with the control group from $309 \mathrm{ml}$ to $196 \mathrm{ml}$ and from $393 \mathrm{ml}$ to $236 \mathrm{ml}$ respectively. Intake of oral rehydration solution and intravenous acetate solution was reduced from $455 \mathrm{ml}$ to $308 \mathrm{ml}$ and from $616 \mathrm{ml}$ to $425 \mathrm{ml}$ respectively. Two patients in the study group compared with 18 patients in the control group required unscheduled rapid intravenous acetate solution to correct signs of dehydration during oral rehydration treatment.

Conclusion-Oral rehydration solution containing L-alanine was considerably better than standard oral rehydration solution at reducing the severity of symptoms and the need for fluid of male patients with diarrhoea associated with $V$ cholerae and enterotoxigenic $E$ coli.

\section{Introduction}

Treatment with glucose based oral rehydration solution is effective for preventing and treating diarrhoea. ${ }^{1-3}$ It does not, however, reduce the volume or frequency of stools or the duration of diarrhoea. ${ }^{+5}$ In 1984 , encouraged by results from several clinical trials, the diarrhoeal diseases control programme of the World Health Organisation began supporting research projects on developing improved oral rehydration solution formulation. ${ }^{6}$ Twenty eight such projects have been completed, are continuing, or are planned. Their aim is to compare the standard WHO oral rehydration solution with other formulations that have the same concentration of salts but may be more effective. There are two types of alternative formulation. One type contains glucose or a glucose polymer and an amino acid or a peptide, or both, in varying concentrations $^{6}$ : this approach was stimulated by studies in children ${ }^{7}$ and adults ${ }^{8}$ that used formulations containing glucose and glycine. In the other type of formulation glucose is replaced by a staple food (cereals, legumes, or roots) as a source of starch and protein: this approach was based on studies that showed that a rehydration solution containing 50 or $80 \mathrm{~g}$ of rice powder per litre in place of glucose can reduce stool volume substantially. ${ }^{910}$

Alanine has been proposed as a component of an improved oral rehydration solution formulation." Studies have shown that it enhances the absorption of sodium and water from the small intestine, the amount of absorption increasing with its concentration..$^{12}$ Alanine is a white, odourless, crystalline powder with a sweetish taste and is soluble in water; it is present in many foodstuffs and has been used as a dietary supplement. ${ }^{13}$ Alanine $50 \mathrm{~g}$ each day orally in divided doses reversed hypoglycaemia and ketosis and reduced catabolism of muscle in obese subjects starved for two weeks. ${ }^{14} \mathrm{~A}$ study of piglets with transmissible gastroenteritis showed that alanine with glucose caused a significantly greater absorption of sodium by the jejunal mucosa than either alanine or glucose alone. ${ }^{15}$

We report the results of a double blind randomised trial of an oral rehydration solution containing glucose and alanine.

\section{Patients and methods}

Male patients aged 6-59 years with a history of watery diarrhoea of 24 hours or less and clinical signs of severe dehydration were included in the study. Criteria for exclusion were: a history of treatment with anti- 